\title{
Percepção dos hábitos alimentares dos estudantes de uma escola de ensino fundamental do município de Jaciara- MT
}

\author{
Perception of eating habits of students of a primary school in the municipality of Jaciara- MT
}

\author{
Eliane de Moura Borges ${ }^{1}$, Danúbia Rodrigues Santos ${ }^{1}$, Jorge Luiz da Silva ${ }^{2}$, Simone da Silva Santos ${ }^{1}$ \\ e Epaminondas de Matos Magalhães²
}

\author{
${ }^{1}$ Graduado (a), Instituto Federal de Educação, Ciência e Tecnologia de Mato Grosso - Campus São Vicente - Núcleo \\ Avançado de Jaciara, MT, Brasil. \\ ${ }^{2}$ Professor, Instituto Federal de Educação, Ciência e Tecnologia de Mato Grosso, MT, Brasil.
}

\begin{abstract}
Resumo
As práticas alimentares são fundamentais ao longo da vida humana, em particular desde a infância. As crianças são mais receptivas aos novos conhecimentos, onde o seu comportamento alimentar é influenciado por diversos fatores, desde o convívio familiar ao escolar. Este estudo tem como propósito refletir sobre a contribuição da escola na promoção de hábitos alimentares saudáveis, por parte dos alunos, realizando revisão bibliográfica nas bases científicas, aulas expositivas e dialogadas, atividades práticas e lúdicas (jogo da amarelinha e jogo da memória), bem como exposição de vídeos. Percebeu-se que uma das maneiras para se contribuir com esta aprendizagem, e também para a qualidade de vida é informar sobre a saúde no ambiente escolar. É neste ambiente que se torna propicio o ensino-aprendizagem relativo aos hábitos alimentares saudáveis. A escola deve funcionar em conjunto com a família com o objetivo de contribuir para a melhor formação do educando, visto que a criança passa boa parte do tempo diário na instituição de ensino. Com este pensamento, preparou-se aulas para alunos do 6. ano, da Escola Estadual Francisco Soares de Oliveira, sobre alimentação saudável, buscando diagnóstico do conhecimento das boas práticas alimentares dos educandos. Aplicou-se aulas sobre os constituintes da pirâmide alimentar, explicando as funções dos principais nutrientes e grupos de alimentos que promovem alimentação saudável. Observou-se que a alimentação dos alunos ainda não é adequada, $e$ que se deve buscar uma melhor maneira de inserir mudanças positivas em suas rotinas diárias. O diálogo favorece então a percepção deste educando sobre seus hábitos alimentares, que durante as atividades lúdicas e os vídeos apresentados expressou-se sobre seus hábitos e o que faria diferença daqui por diante. O resultado esperado foi gratificante, percebeu-se que o educando assimilou o que se pretendia com este trabalho.
\end{abstract}

Palavras-chave: Práticas pedagógicas. Alimentação saudável. Ambiente escolar

\begin{abstract}
Feeding practices are critical throughout human life, particularly since childhood. Children are more receptive to new knowledge where your eating behavior is influenced by several factors, from family life to school. This study aimed to reflect on the school's contribution in promoting healthy eating habits, by the students, conducting literature review in the scientific bases, exhibition and dialogued classes, practices and recreational activities (game of hopscotch and memory game), as well as exhibition videos. It was felt that one way to contribute to this learning and also to the quality of life is to report on health in the school environment. It is in this environment that becomes conducive teaching and learning concerning healthy eating habits. The school should work together with the family in order to contribute to better education of the student, as the child spends much of her time every day in the teaching institution. With this thought, prepared lessons for students of the 6th year, the State School Francisco Soares de Oliveira, on healthy eating, trying to diagnose the knowledge of good eating habits of students. Applied lessons on the constituents of the food pyramid, explaining the functions of key nutrients and food groups that promote healthy eating. It was observed that the power of students is not adequate and that we should seek a better way to enter positive changes in their daily routines. The dialogue then favors the perception of student about their eating habits, which during play activities and the submitted videos was expressed about their habits and what would make a difference going forward. The expected result was satisfying, it was noticed that the student has assimilated what was intended with this work.
\end{abstract}

Keywords: Pedagogical practices. Healthy eating. School environment 


\section{Introdução}

Em se tratando de hábitos alimentares, a criança é influenciada por diversos fatores inerente ao meio em que ela está inserida, entre estes destacam-se o círculo familiar e o ambiente escolar. À medida que a criança passa a frequentar a escola e a conviver com outros educandos, ela diversificará seus conhecimentos sobre outros tipos de alimentos, preparações e receberá influências em seus hábitos (MAINARDI, 2005).

Também é na escola que o educando, ao estudar a disciplina de Ciências de educação e saúde, entra em contato com os conceitos de boa alimentação, o que pode causar mudanças em seus hábitos alimentares e na vida social (RODRIGUES, 2011). Sendo assim, a disciplina de Ciências, componente curricular do ensino fundamental, vem assegurar uma melhor orientação na aprendizagem do educando.

Para isso, as principais estratégias incluem a promoção de um estilo de vida ativo e o estímulo para a adoção de hábitos alimentares saudáveis, promovendo maior consumo de frutas e hortaliças, restringindo a ingestão de alimentos pobres em nutrientes, tais como: lanches e guloseimas, e fornecendo informações necessárias para que o aluno seja capaz de realizar escolhas alimentares saudáveis (TORAL e SANTOS, 2006).

O acesso as informações viabilizará melhor o poder de escolha do educando para o hábito e práticas alimentares saudáveis, por isso este trabalho, realizado em uma escola de ensino fundamental do município de Jaciara, buscou observar os conhecimentos dos alunos sobre quais alimentos são mais e menos saudáveis, bem como suas proporções de consumo, respeitando a identidade cultural e social de cada um.

Assim, investigou-se as atividades relacionadas à educação alimentar dos alunos de uma sala do $6^{\circ}$ ano do ensino fundamental de uma escola no município de Jaciara-MT. Abordando os seguintes questionamentos: identificar as atividades voltadas à educação alimentar na escola, identificar os hábitos alimentares saudáveis dos alunos e se os professores trabalham em suas aulas os conceitos de má e boa alimentação e as suas consequências.

\section{$2 \mathrm{O}$ ensino de ciências naturais}

O Ensino de Ciências, afirmado pelo Parâmetros Curriculares Nacionais (PCNs), por muito tempo foi feito como mera transmissão de conhecimento, através de aulas expositivas, em que o aluno tinha o dever de reproduzir os conhecimentos cumulativos passados pelo docente, sem participar ou questionar sobre o assunto, não havendo, portanto, entre ambos está interação e, consequentemente, com o conteúdo, desta forma, desconsiderando os conhecimentos prévios dos alunos (BRASIL, 2000).

Ainda nessa perspectiva, a concepção de ensino de qualidade era representada exclusivamente pela figura do aluno que conseguisse arquivar, isto é, decorar tudo que o professor pronunciava, como devolutiva na avaliação (CAMPOS, 2009).

Ainda segundo Paulo Freire,

O educando não é uma tabula rasa, um "recipiente vazio" que se deva encher de conteúdo, o chama de educação bancária. Para ele, educar é construir o sujeito em transformação, sendo isso que consideramos de educação plena (FREIRE, 1996, p. 30).

O Parâmetros Curriculares Nacionais ( $\mathrm{PCN}^{\prime} \mathrm{s}$ ) apontam ainda como um de seus objetivos referente ao ensino de Ciências, o de saber utilizar diferentes fontes de informação e recursos tecnológicos para adquirir e construir conhecimento. Diante desta concepção, o docente precisa buscar metodologias e utilizar fontes de informações que contribuam com a aprendizagem do educando, e que o possibilite a contemplar com o olhar construtivo E crítico- reflexivo (BRASIL, 2000). 
A proposta deste estudo é construída numa visão crítica e embasada na ação da prática pedagógica, no contexto da educação em Ciências para educação básica na realidade em questão, buscando propiciar ao educando uma abordagem do conhecimento científico de forma interdisciplinar, superando o conteudismo (conteúdo pelo conteúdo) e desenvolvendo habilidades e competências básicas de cidadania; a construção e a leitura dos conceitos de Ciências em seu cotidiano, senso de observação, reflexão e ação (MELLO, 2011).

Ainda assim Morin (1999) afirma que,

\begin{abstract}
Uma das formas de se trabalhar a interdisciplinaridade voltadas para o ensino de Ciências são aulas experimentais, é mediante a realização de pequenas tarefas com o desenvolvimento do conteúdo que o educando vem a abranger as temáticas das Ciências Naturais. (MORIN, 1999, p.56).
\end{abstract}

Aulas experimentais devem ser um recurso pedagógico de constante utilização. Essas atividades, praticadas fora da escola, favorecem a interação disciplinar através de uma abordagem de temas socioculturais relevantes para a compreensão da realidade (CASTRO, 2012).

Os educadores conhecem e convivem diariamente com seus alunos em uma relação simultânea de construção de conhecimento e de troca, sendo importante na configuração e no estabelecimento da educação alimentar e hábitos saudáveis por parte do educando. Para tanto, reforça-se que o conhecimento e a reflexão do educador no âmbito desta temática são essenciais (DOMENE, 2008).

Pimenta (2005, p. 39) conclui que "trabalhar as informações na perspectiva de transformá-las em conhecimento é uma tarefa primordial da escola".

\title{
3 Alimentação saudável
}

De acordo com a busca por maior qualidade de vida, parece ser um dos principais objetivos: o alimentarem-se com saúde, consumindo-se assim uma variedade de alimentos (cereais, leite e derivados, carnes, pão, massas, frutas, legumes e vegetais), tomarem muito líquido, limitar o consumo de alimentos ricos em açúcar, gordura e colesterol, controlarem o consumo de bebidas alcoólicas, chá, café e outras bebidas que contenha cafeína, diminuir a quantidade de sal (sódio) nos alimentos, e controlar o peso (VILAR, 2002).

Sendo assim, Freitas destaca:

\footnotetext{
Alimentação saudável é um dos fatores predominantes em nossa saúde, pois somos constituídos por aquilo que comemos. Nosso sangue, nossos nervos, nossos músculos, todas as nossas células são constituídas e renovadas de acordo com o que ingerimos (FREITAS, 2002, p.15).
}

A alimentação se faz importante para manter a saúde e prevenir doenças, em suma a ausência destes constituintes pode causar transtornos ou distúrbios, podendo levar até a morte.

De acordo com Freitas (2002, p.15), "a alimentação influi em nossa disposição, em nosso estado emocional e até em nossa inteligência". Todo esse contexto pode prejudicar o interesse do educando em frequentar a escola, apresentando baixo rendimento, irritabilidade, agitação, estresse e apatia. Portanto, entendendo melhor o que acontece com a aprendizagem do ser humano é possível perceber e discutir quais são os fatores causadores ou que contribuem com a dificuldade de aprendizagem.

Na construção do conhecimento sobre a alimentação saudável, devem ser compreendidos, principalmente, no ensino fundamental, os hábitos alimentares dos alunos, bem como o estudo dos nutrientes e constituintes dos alimentos.

Sobre os conceitos de alimento, Gowdak (2006) descreve: 


\begin{abstract}
Alimento - entende-se por alimento todo material nutritivo, isto é, aquele que fornece substâncias para manter o organismo com vida. Tais substâncias, denominadas nutrientes, podem ser classificadas quanto à composição química e quanto à função que desempenha no organismo (GOWDAK, 2006, p.64).
\end{abstract}

Nos primeiros anos de idade, além do leite materno, a criança já deve ser alimentada inclusive de 03 três a 05 cinco refeições diárias, contendo os nutrientes, proteínas, açúcares gorduras, vitaminas e sais minerais, que podem ser encontrados em alimentos, como leite, suco e água (PASSOS, 1996).

Assim sendo Gowdak destaca a importância dos alimentos:

\begin{abstract}
Precisamos de alimentos porque neles encontramos tudo aquilo de que o nosso corpo necessita para a obtenção de energia, de nutrientes e de materiais de construção, de novas células de reparo e de componentes celulares para a regulação de funções e prevenção contra várias doenças (GOWDAK, 2006, p.32).
\end{abstract}

Uma alimentação saudável, não precisa ser de custo elevado, pois os alimentos necessários devem ser obtidos nos padrões definidos, social e culturalmente como fundamento básico, ou seja, alimentos de baixo custo e de boa acessibilidade, como o popular arroz e feijão, apresentam bons teores de nutrientes. "É importante que a família e os professores conversem sobre esse tema, pois todos devem ter uma alimentação de qualidade" (SALGADO, 2005, p17).

\title{
4 Prática alimentar
}

Em geral, a alimentação saudável é sempre constituída por três tipos de alimentos básicos: alimentos com alta concentração de carboidratos, como os grãos (incluindo arroz, milho e trigo), pães, massas, tubérculos (como as batatas e o inhame) e raízes (como a mandioca);

De acordo com o guia alimentar para a população brasileira, (ORGANIZAÇÃO PANAMERICANA DE SAÚDE):

\footnotetext{
Para serem consideradas refeições saudáveis a mesma deverá ser preparada com alimentos variados, com tipos e quantidades proporcionais às fases do curso da vida, se tornando assim refeições coloridas e saborosas incluindo também os alimentos de origem vegetal e animal (BRASIL; ORGANIZAÇÃO PAN-AMERICANA DE SAÚDE, 2006, p.25)
}

Estas, importantes fontes de energia são os principais componentes da maioria das refeições.

Frutas, legumes e verduras ricos em vitaminas minerais e fibras, estando presentes diariamente nas refeições, contribuem para proteção à saúde, contribuindo também para proteção contra as doenças crônicas não transmissíveis (DCNT) e potencialmente fatais, como: diabetes, hipertensão, acidente vascular cerebral, doenças cardíacas e alguns tipos de câncer.

As leguminosas, como feijões, e as oleaginosas, como as castanhas e sementes, são alimentos fundamentais para a saúde. O preparo típico brasileiro, feijão com arroz é uma combinação alimentar saudável e completa.

Nas proteínas temos o leite e derivados, carnes e ovos, gorduras, açúcares e sal (ORGANIZAÇÃO MUNDIAL DE SAÚDE, 2004).

Como propostas de inclusão às práticas alimentares, se tem os projetos pedagógicos escolares, nos diferentes níveis de ensino, com isso, a difusão do termo "promoção das práticas alimentares saudáveis", desde o final dos anos de 1990, passou a fazer parte dos documentos oficiais brasileiros (SANTOS 2005)

\section{Educação alimentar na escola}

Os educadores devem ajudar o a educando a reconhecer e identificar os alimentos, conduzindo-os de forma prazerosa, estimulando-os em suas iniciativas, para desde cedo promovendo a conscientização da prática de uma boa alimentação. 
O processo educativo, com ajuda da escola, é fundamental também para que a criança tenha ferramentas para fazer suas próprias escolhas. Este aprendizado alimentar será a sua base, sobre tudo na adolescência, quando se inicia o processo de maior independência.

Ainda segundo Franques (2007),

É na escola parte a ser trabalhada no sentido educacional e vivencional, pois depois da família é a grande "formadora" na vida da criança; sendo onde geralmente ela passa a maior parte de seu dia. É na escola que é dada a oportunidade de se colocar a criança uma reeducação alimentar, atividades físicas e mudanças comportamentais em ambiente otimista, acolhedor e com possibilidade de cumplicidade entre todos os envolvidos ( FRANQUES, 2007, p. 01)

Nos moldes do Parâmetros Curriculares Nacionais (PCNs) está estabelecido e constituído desde 1997, o plano oficial para o ensino fundamental, e tem como propósito embasar o desenvolvimento de práticas voltadas à reflexão, valorização das diversidades e resgate da cultura alimentar, assegurando que a formação do conhecimento, entre outras coisas, promova a alimentação saudável (BRASIL, 2012)

Segundo Evangelista, citado por Neves (2009, p. 34) "os alimentos devem conter, em sua composição, nutrientes capazes de suprir as necessidades básicas do organismo: plástica, energética e reguladora."

Assim sendo, Freitas adverte que alguns conceitos devem ser lembrados:

Nutrientes - São sustâncias que existem nos alimentos que fornecem compostos essenciais ao
nosso organismo, são eles: proteínas, hidratos de carbono, gorduras, vitaminas, minerais, água,
fibras". Proteínas - As proteínas são substâncias que entram na composição dos alimentos e que
servem para construir e reparar os tecidos do corpo humano: músculos, tendões, ossos, pele,
sendo indispensáveis para o crescimento. (Freitas 2002, p.15)

"Alimentos como fontes de energia, glicídios lipídios e proteínas, são nutrientes plásticos, Sendo assim a pirâmide tem o papel de orientar quanto às porções diárias necessárias no organismo, para que se tenham bons hábitos alimentares no decorrer de sua vida" (FREITAS, 2002, p.43).

A promoção da saúde permite que as pessoas adquiram maior controle sobre a própria qualidade de vida. Através da adoção de hábitos saudáveis não só os indivíduos, mas também seus familiares e comunidade se apoderam de um bem, um direito e um recurso aplicável à vida cotidiana. Baseado nesse conceito de integração entre grupos de indivíduos a Organização Mundial da Saúde OMS (1997, p. 3), define que "uma das melhores formas de promover a saúde é através da escola".

A escola é um espaço social onde pessoas convivem, aprendem e trabalham, onde o educando e professores passam a maior parte de seu tempo. Além disso, é na escola onde os programas de educação e saúde podem ter sua maior repercussão, beneficiando os alunos na infância e na adolescência. Nesse sentido, os professores e todos os demais profissionais tornam-se exemplos para os alunos, suas famílias e para a comunidade na qual estão inseridas.

A alimentação equilibrada e balanceada é um dos fatores fundamentais para o bom desenvolvimento físico, psíquico e social da criança, e a alimentação de todos os indivíduos deve obedecer as "Leis da Nutrição" descritas por Pedro Escudero (SILVA, 1998). Sabendo que este comportamento de alimentação resulta no desenvolvimento necessário desde que se tenha os devidos cuidados.

Os alimentos são classificados em grupos básico, de acordo com os nutrientes necessários ao organismo; são eles grupos ordenados que constituem a Pirâmide dos alimentos (Figura 1), podendo assim promover uma maior conhecimento sobre os alimentos, suas principais fontes e nutrientes, servindo de orientação para uma boa alimentação (FREITAS, 2002).

Neste Sentido Freitas conceitua os nutrientes:

"1-PROTEÍNAS - são alimentos construtores ou reparadores. Eles renovam nossas células gastas e constroem novos tecidos (FREITAS, 2002, p.43)." 


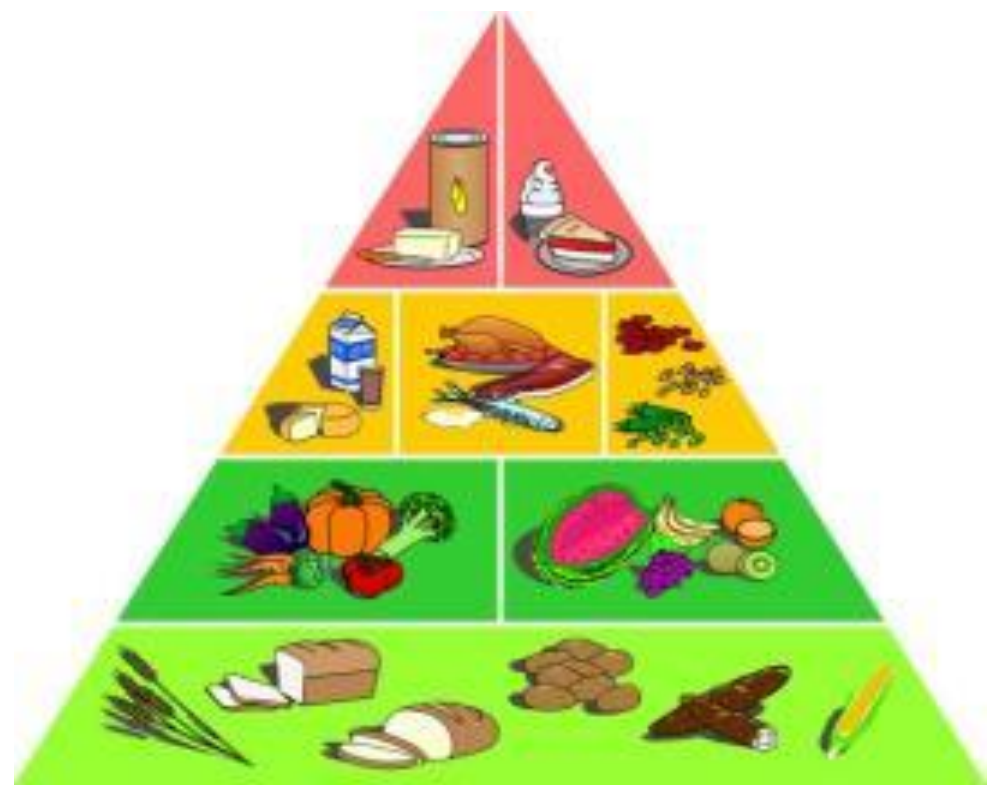

Figura 1- Pirâmide Alimentar (IRLA, 2001)

Neste Sentido Freitas conceitua os nutrientes:

"1-PROTEÍNAS - são alimentos construtores ou reparadores. Eles renovam nossas células gastas e constroem novos tecidos (FREITAS, 2002, p.43)."

“2- LIPÍDEOS - também são energéticos e veiculadores de certas vitaminas lipossolúveis. São também essenciais ao corpo (FREITAS, 2002, p.43)."

"3-VITAMINAS - ou reguladores do funcionamento do corpo. Elas não fornecem energia, sua função é manter o organismo funcionando corretamente, por meio do auxílio nos processos metabólicos (FREITAS, 2002, p.45)."

"4-MINERAIS - assim como as vitaminas, são reguladores. Exercem importante papel na manutenção do organismo. Estão presentes em toda parte do corpo interferindo no equilíbrio das funções vitais do sistema nervoso bem como de todo organismo (FREITAS, 2002, p.43)."

"5-CARBOIDRATOS - são energéticos, sendo a principal fonte de combustível do corpo. Fornecem as calorias que gastamos diariamente em nossas atividades (FREITAS, 2002, p.47)."

\section{Metodologia da Pesquisa}

Este estudo consistiu em uma pesquisa com abordagem qualitativa do tipo descritiva de acordo com metodologia descrita por Lüdke e André (1986). O método de observação e intervenção ocorreram, durante o mês de agosto de 2014, na escola estadual de ensino fundamental Francisco Soares de Oliveira, situada na área urbana, do município de Jaciara - MT, e que não dispunha de cantina comercial. O grupo estudado foi composto por 30 alunos do $6^{0}$ ano do ensino regular, com idade entre 12 e 13 anos.

A intervenção foi realizada nas seguintes etapas:

\subsection{Questionário designados a professores de Ciências}

Foi aplicado questionário (Quadro 1), contendo perguntas sobre alimentação saudável aos professores de Ciências. Ressalta-se que a escola em estudo apresenta 3 (três) professores na área especifica, os quais responderam às perguntas, expressando suas opiniões sobre o ensino dos alimentos e práticas saudáveis de alimentação. 
QUADRO 1- Questionário avaliativo aplicado aos docentes

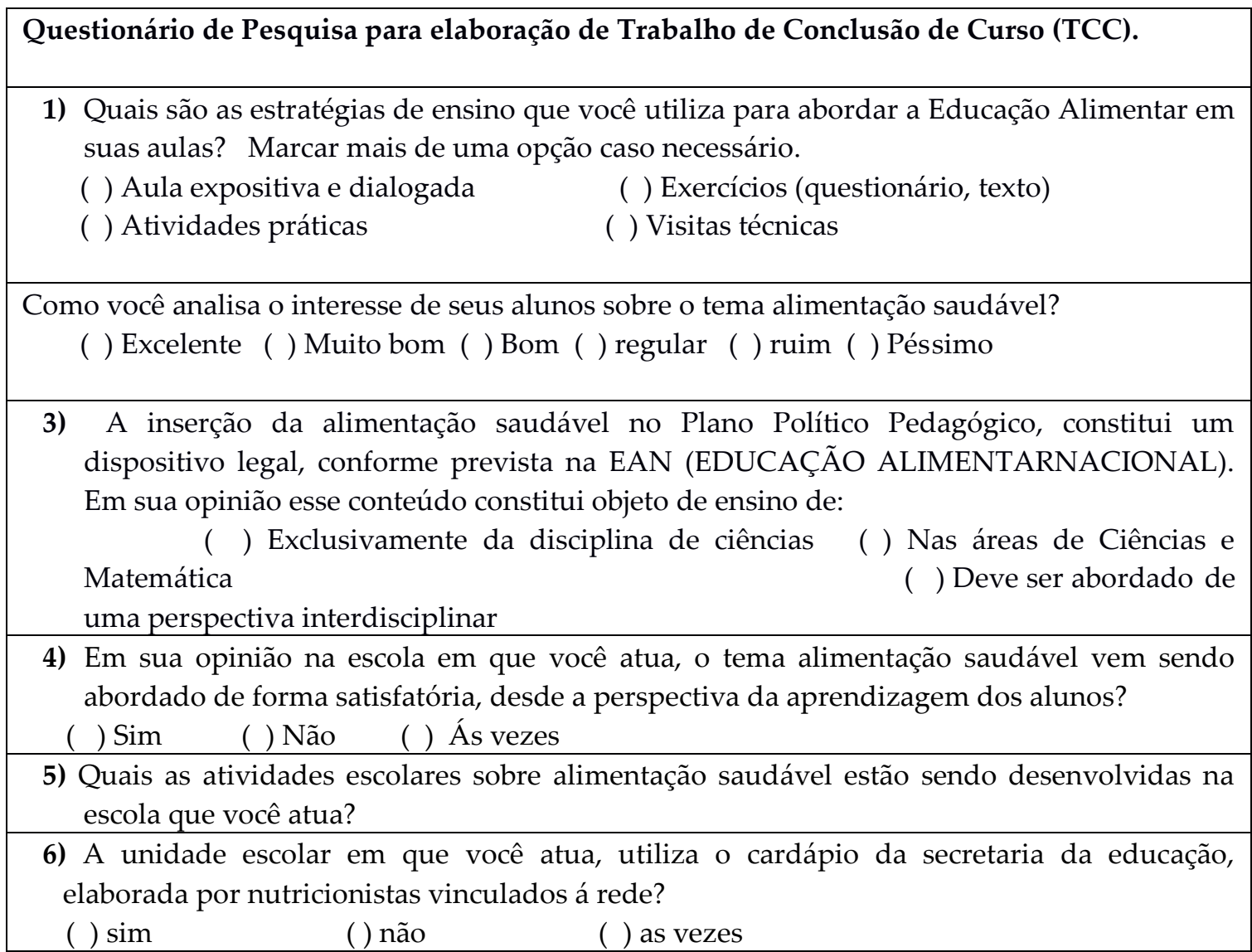

\subsection{Aulas dialogadas e expositivas}

Foram realizadas um total de 4 aulas (de 50 minutos cada) expositivas e dialogadas para os alunos do $6 . \stackrel{\mathrm{o}}{\text { ano. }}$

\section{- Aula 01: Conceitos e definições}

A aula iniciou-se com uma conversa informal sobre alimentação saudável, onde explicou-se para os alunos, a importância de consumirem alimentos saudáveis como frutas, verduras, legumes e sua correlação com a saúde.

Explicou-se sobre os conceitos dos nutrientes que compõem os grupos de alimentos da pirâmide alimentar (proteínas, carboidratos, lipídeos, sais minerais e vitaminas), enfocando suas principais características, funcionalidades e recomendações de consumo.

Vale ressaltar que o conteúdo foi ministrado por partes (trabalhando primeiramente cada nutriente de forma isolada), dando melhor compreensão ao educando e proporcionando uma melhor correlação entre aluno-professor-conteúdo, onde a cada momento os professores chamavam a discussão em grupos sanando dúvidas.

\section{- Aula 2: Exibição de vídeos sobre práticas alimentares saudáveis}

Nesta aula, foram apresentados e discutidos vídeos sobre a importância dos alimentos. Os vídeos apresentados em sala têm pequenos comentários de especialistas sobre alimentação saudável, apontando quais alimentos fazem bem a saúde, e quanto e como se deve utilizar destes, para que não venham atrapalhar as funções do organismo.

Nesse momento, abriu-se espaços de diálogo, onde os educandos realizaram questionamentos sobre o conteúdo visto, facilitando assim a sua aprendizagem. Como avaliação foi determinado que os 
alunos escrevessem em seu caderno o que mais lhe chamaram a atenção do conteúdo apresentado em vídeo, tornando isto indispensável para a aprendizagem sobre o tema em discussão.

- Aula 3: Utilização de desenhos ilustrativos sobre hábito alimentar saudável.

Nessa aula, foi solicitado aos alunos que desenhassem os alimentos que costumam consumir com frequência em seu dia-a-dia.

\section{- Aula 4: Realização de jogos pedagógicos e aula prática}

Nessa aula, realizou-se jogos pedagógicos como o intuito de revisar o conteúdo de forma lúdica e divertida. Nesta etapa foram trabalhados os jogos de amarelinha e o jogo da memória (perguntas e respostas).

Também realizou-se aula prática na horta da escola.

\section{- Amarelinha}

Teve como objetivo associar os conceitos de hábito alimentar e alimentação saudável, através da brincadeira da amarelinha (Figura 2), tendo perguntas baseada na pirâmide alimentar e nos conceitos de seus constituintes. Esta sequência de atividades se justifica também como uma interessante e divertida forma de cultivo e valorização do lúdico no processo de ensino-aprendizagem.

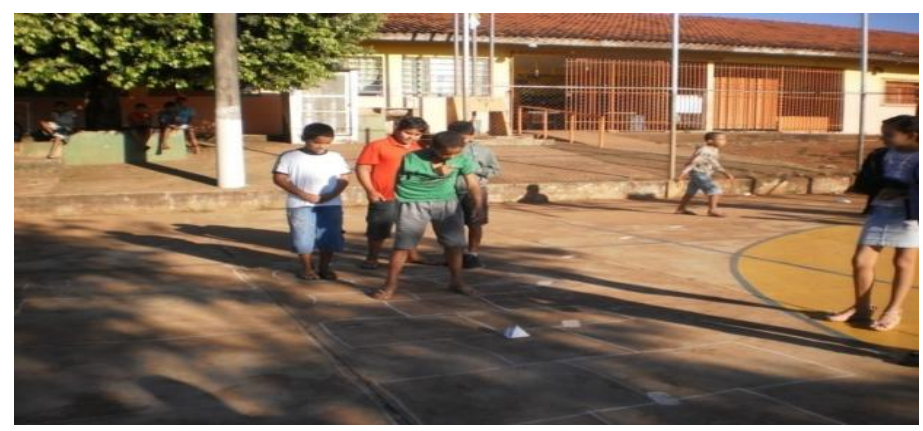

Figura 2 - Alunos jogando amarelinha

\section{- Horta}

Os alunos foram levados à horta da escola (Figura 3), onde realizaram a identificação dos alimentos ali plantados, bem como fizeram o plantio de algumas verduras.

Também deve-se destacar que neste momento os professores explicaram os cuidados com o solo, a sua conservação, fertilidade e relação com a planta.

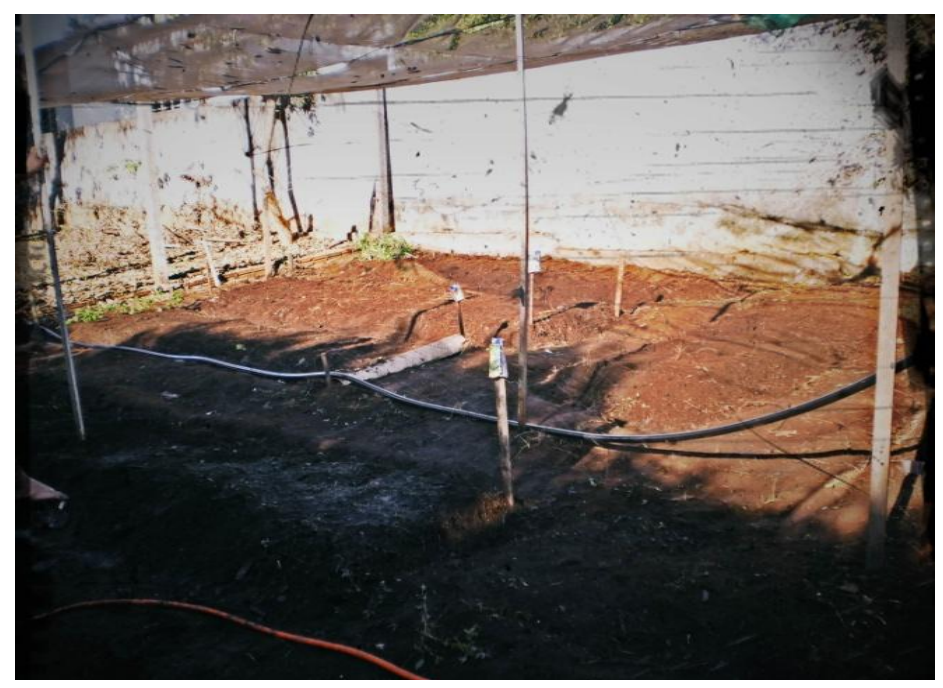

Figura 3 - Horta da escola 


\section{Resultados e Discussões}

\section{Etapa 1: Questionário designados a professores de Ciências} escolar.

Com o questionário percebeu-se que a alimentação saudável é muito importante na vida

Este desenho feito de forma grafitada compunha-se de frutas e legumes, mostrando pouco conhecimento dos alimentos que estão na pirâmide de alimentos. Sabe-se que educando no decorrer de sua vida, opta por suprimir o alimento correto e essencial, por talvez encontrarem opções de fácil acesso ou porque as embalagens do produto chamam sua atenção, tornando-os vulneráveis e até colocando suas vidas em situação de risco.

\section{Etapa 2: Aulas expositivas e dialogadas}

Com a aplicação das aulas, percebeu-se que o seu conteúdo deve estar adequados ao contexto geral de vida do educando, e voltado para a percepção dos bons hábitos alimentares e da alimentação saudável.

Observou-se que muitos alunos apresentaram pouco conhecimento sobre os conceitos dos nutrientes presentes nos alimentos, porém, a partir do momento em que o tema era elucidado, alguns alunos reconheciam a importância de certos alimentos para a manutenção da saúde, o que nos leva c concluir que mesmo sem entender, na sua totalidade, os conceitos das substâncias componentes de um alimento, os alunos trazem uma noção sobre a importância dos mesmos.

Durante a discussão da pirâmide alimentar, notou-se que os alunos conseguiram associar a importância dos grupos de alimentos, bem como as suas quantidades diárias de ingestão.

A pirâmide alimentar, segundo Philippi (2000), nos dá dicas de como fazer uma alimentação saudável, ressaltando que as recomendações diárias de alimentação são feitas para atender os indivíduos, variando conforme idade, sexo e atividade física, pois as necessidades de energia são diferentes para cada pessoa.

Na discussão do conceito de proteínas, e quais alimentos estes nutrientes são encontrados, observou-se que logo, os alunos, compreenderam que a proteínas são as substâncias reparadoras dos tecidos do nosso corpo, onde afirmavam a sua função de manter o corpo saudável. Também destacase que os alunos apontaram algumas fontes de proteína, tais como o leite, feijão, ovos e carnes.

Os alunos também apresentaram bom entendimento sobre os carboidratos e sua função como base na pirâmide alimentar.

A base principal de nossa alimentação deve estar nos carboidratos, assim sendo Freitas,

Recomenda que $60 \%$ a $70 \%$ da nossa energia devem vir dos carboidratos, e que nosso cérebro consome cerca de $30 \%$ da energia do organismo. Daí a grande necessidade de termos um amplo suprimento de carboidratos. (FREITAS, 2002, p.49).

Sobre os carboidratos, as crianças logo associaram ao leite (lactose), no açúcar e frutas, as quais o nosso organismo tem necessidades. Sobre a importância dos lipídios, os alunos apontaram suas fontes, que são encontrados na manteiga e óleos os quais se utilizados em excesso são prejudiciais ao organismo, promovendo doenças, como hipertensão, diabetes e pressão e colesterol alto.

Segundo Freitas (2002, p.64) "o melhor e mais seguro seria usar alimentos em seu estado natural, sem transformações químicas [...] a gordura saturada de origem animal por estado natural, sem transformações químicas [...] a gordura saturada de origem animal, por seu elevado teor de colesterol é inconveniente para a alimentação humana. 
Com relação ao tipo de vitamina, os alunos conseguiram compreender as suas funções, bem como as causas de um provável excesso (Quadro 2)

Quadro 2. Tipos de Vitaminas: Distúrbios e fontes

\begin{tabular}{|l|l|l|}
\hline Tipos de Vitaminas & Falta de Distúrbios & Onde é encontrada \\
\hline Vitamina A & Visão prejudicada & $\begin{array}{l}\text { Cenoura, leite, ovo, manteiga, queijo, } \\
\text { óleo de fígado de bacalhau. }\end{array}$ \\
\hline Vitamina B & $\begin{array}{l}\text { Muito cansaço e falta } \\
\text { de apetite }\end{array}$ & $\begin{array}{l}\text { Verduras, ovo, fígado de boi, arroz } \\
\text { integral, trigo. }\end{array}$ \\
\hline Vitamina C & Escorbuto & Acerola, limão, laranja, abacaxi, caju, mara \\
\hline Vitamina D & $\begin{array}{l}\text { Raquitismo ou } \\
\text { alterações no } \\
\text { desenvolvimento } \\
\text { ósseo em crianças }\end{array}$ & $\begin{array}{l}\text { Ovo, óleo de fígado de bacalhau, leite, } \\
\text { Peixe }\end{array}$ \\
\hline
\end{tabular}

Vale ressaltar que de acordo com cada pergunta a resposta é colocada com cautela levando-as a entender que o principal é como conciliar hábitos alimentares com costumes adquiridos, exaltando sempre que bons hábitos devem ser cultivados desde os primeiros anos vida.

Neste sentido foi que quando os alunos desenvolveram desenhos ilustrativos sobre os alimentos que consumiam (Figura 4), pode perceber que os mesmos conseguiram correlacionar a boa alimentação com alimentos do seu dia-dia.

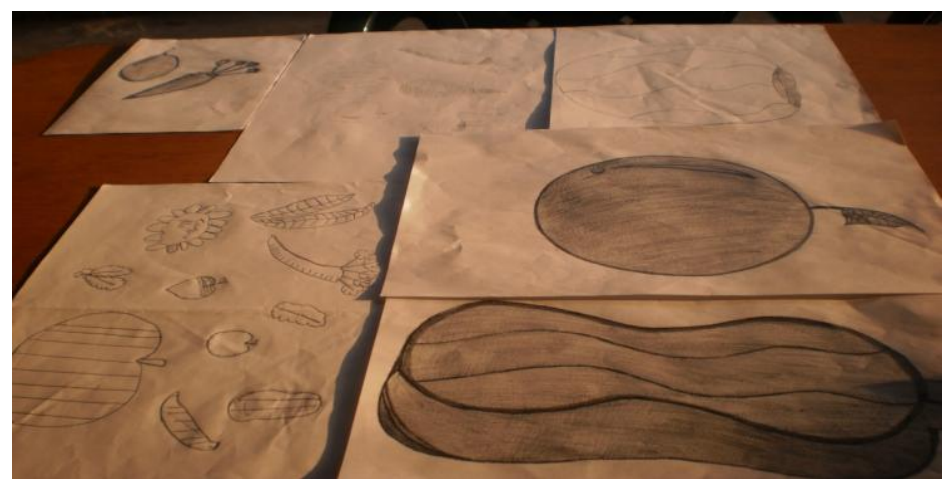

Figura 4 - Desenho grafitado dos alimentos consumidos no dia-a-dia dos alunos

O desenho ilustrativo em grafite e a demonstração do entendimento pelo educando, no desenvolvimento da aula. Percebeu-se nesse momento que ao desenhar já se estabelece a relação entre os bons hábitos alimentares que beneficia a sua saúde.

Após a apresentação dos vídeos, percebeu-se que os alunos tinham pouco conhecimento dos constituintes apresentados no material. Portanto, o término desta apresentação, o educando escreveu em seu caderno o que de mais importante do vídeo levaria pra sua vida. Muitos Relataram que levariam a explicação de como se alimentar bem e de como melhorar os hábitos adquiridos.

Deparando com o conteúdo aplicado percebeu-se que os alunos haviam compreendido melhor o conteúdo, quando produziram textos. A professora decidi então por fazer a aplicação lúdica buscando a participação de todos que no momento estavam presentes. 
Durante a realização do jogo da amarelinha, os educandos surpreenderam com respostas satisfatórias, sabendo que nem sempre se conseguem situar todo o conceito na memória dos adolescentes, acredita-se que depois desta aula os alunos irão sim ter bons hábitos alimentares, notouse que mesmo antes de terminar a aula, queriam saber mais do conteúdo havendo despertado interesse em compreender este conteúdo.

A utilização de práticas e jogos são muito importante para o ensino aprendizagem do aluno, na medida em que se percebe qual é o sentido dos bons hábitos da alimentação saudável.

\section{Conclusões}

As atividades direcionadas, significativas e criativas aplicadas no decorrer desta pesquisa, buscam relatar a importância da qualidade de vida a partir de uma alimentação adequada, ressaltando que o contrário desta, pode-se causar inúmeros malefícios à saúde humana, independente da idade.

Verifica-se que a alimentação saudável se aprende na escola, e que na infância é o período ideal para a construção da percepção dos hábitos alimentares e da alimentação saudável, por parte dos alunos da escola analisada.

Outra preocupação observada foi com o papel do educador em decorrência desta responsabilidade, muitas das vezes é cobrado dos mesmos sobre todos os conteúdos e disciplinas, e este necessitando dar conta durante o ano, contudo, acredita-se que se pode trabalhar com a educação alimentar por meio do próprio currículo, na interdisciplinaridade utilizando dos alimentos como base, para a introdução das disciplinas.

Outra forma também pode ser por meio do currículo extra, a partir de projetos estruturados por meio de hortas, pirâmide alimentar, enfim, de forma significativa e prazerosa para o aluno.

Concluí-se, portanto, com o presente trabalho, que o educador e a escola devem ser parceiros com a família, promovendo a educação alimentar de qualidade, sobre tudo a escola tem em mãos, poderosas ferramentas, como a educação sistematizada e a merenda escolar, contra os maus hábitos alimentares.

Acreditando nisto é que o educador tem as possibilidades de ser o agente promotor de mudanças significativas, pois com a verificação inicial sobre a alimentação inadequada, dos 30 alunos da referida escola, a partir da intervenção já se percebe a conscientização dos mesmos para a educação alimentar saudável, sabendo que essa educação leva tempo, e que é necessária para que o aluno tenha melhor qualidade de vida.

\section{Agradecimentos}

À Coordenação de Aperfeiçoamento de Pessoal de Nível Superior (CAPES) pelo subsídio através do Programa de Consolidação das Licenciaturas (PRODOCENCIA) Edital 019/2013, processo № 113.657, e do Programa Institucional de Bolsa de Iniciação à Docência (PIBID) Edital № 061/2013, processo № 128.570, IFMT/Campus São Vicente/Sub Projeto Ciências.

\section{Referências}

AMARAL, C.M.C. Educação alimentar. FMPB, 2008. Disponível no site: Fundação Passos Barros / acesso em 22/06/2008. 
BRASIL. Conselho Nacional de Educação. Parecer CEB n. 11/2000. Diretrizes Curriculares Nacionais para a Educação de Jovens e Adultos. Brasília, 10 de maio de 2000

BICUDO, Maria Aparecida; SILVA JUNIOR, Celestino Alves (Org.) Formação do educador: dever do Estado, tarefa da Universidade. São Paulo: (UNESP, 1996).

Cromack LMF, Bursztyn I, Tura LFR. O olhar do adolescente sobre saúde: um estudo de representações sociais. Ciências Saúde Coletiva 14: 627.34, 2009

FREITAS, Paulo G. Saúde um Estilo de Vida. Baseado no Equilíbrio de Quatro Pilares. São Paulo.

FREITAS, M.C.S., Educação nutricional: aspectos socioculturais. Nutrição, Campinas Guias alimentares para crianças: aspectos históricos e evolução. Rev. Nutr.

[On line].2006, vol.19, n.2, pp. 255-263.ISSN 1415-5273

BRASIL. Lei das Diretrizes e Bases da Educação Nacional (LDBEN): lei no 9.394, de 20 dezembros 1996.

LIMA, Gabriela Guirão Bijos. O educador promovendo hábitos alimentares saudáveis por meio da escola. 100f, 2008- UNESP, Bauru, 2008.

MAINARDI, N. A ingestão de alimentos e as orientações da escola sobre alimentação, sob oponto de vista do aluno concluinte do Ensino Fundamental. 150p. Piracicaba, 2005.

MELO M. B. de et al. Qualificação de agentes comunitários de saúde: instrumento de inclusão social. Trabalho, Educação e Saúde, Rio de Janeiro, 7(3), 463-477, 2009-2010.

SANTOS, Ligia Amparo da Silva. O fazer educação alimentar e nutricional: algumas contribuições para reflexão. Ciência \& Saúde Coletiva, v.17, n.2, p. 455-462. 2012.

SAVIANI, Demerval. Os saberes implicados na formação do educador. In: SALGADO, JocelemMastrodi. Alimentos Inteligentes: saiba como obter mais saúde por meio da alimentação. São Paulo: Prestígio, 2005. ISBN 85-99170-20-1

TARDIF, Maurice. Saberes profissionais dos professores e conhecimentos universitários THOMPSON, Jonh B. Ideologia e cultura moderna: teoria social crítica na era dos meios de comunicação de massa. Petrópolis, RJ: Vozes, 1995.

VASCONCELLOS, C. Construção do Conhecimento em Sala de Aula. 13aㅡ Edição. Editora Libertad, São Paulo, 2002. 